\title{
Considerations on the Human Body in European Art from Ancient Times to Present Day
}

\author{
Liviu Nedelcu*
}

\begin{abstract}
The present considerations on the human body tried to place the exploration of the topic in its radically cultural dimension, hence the references to the body being already addressed to the anthropomorphic, descriptive, symbolic sign completely emerged in artistic exercise. We outlined artistic findings from old times to contemporaneity wherever the motive of the human body was central in this selection; furthermore, the nude has made and still makes the subject of convergent discourses on its representation, intensity or weakening of its capacity for signifying. Land of inexhaustible negotiation between nature and culture, available to primitivism, always found again as more sophisticated, transformed by the demands imposed throughout history, ideals and illusions, the body imposes itself on cultural conscience as an irreducible challenge. This paper is consecrated to the nude and aims at overviewing a large series of investigations from European art on the topic. I believe that from more ancient times to contemporaneity, the human body proved to be an excellent landmark in the approach of any artist; moreover, this seduction will continue to exert itself on the upcoming artists, irrespective of the future's artistic tendencies. The fact that, in time, the human figure has been an extremely important motive for the artistic laboratory determined me to choose this topic; in addition, throughout the article, I have attempted to prove the interest in the nude, recalling the most important tendencies and manifestation from old times to contemporaneity.

In this approach, we started from the finding, which has actually marked many years of my creation, that the human body may show itself in a sacred and profane hypostasis; as a result, this study was structured to account for the two dimensions. Along the documentation and drafting, I realized that, in fact, the human body can only be sacred even in its nude hypostasis. The purpose of the present paper is far from exhausting the problematic of the human body; its aim is to draw attention to the importance of the topic.

The concerns on this topic have taken various forms throughout art history. We brought into play the significance of the human body in Old Greeks quoting Thucydides who argued that the difference between Greeks and barbarians was marked in a civilising way since nudity had become the rule in the Olympic Games; I wrote on Christian art during the first centuries AD, then about the art of the Middle Ages which brought profound changes to the
\end{abstract}

\footnotetext{
* Manager of Vrancea Cultural Center, Assoc. Prof., Faculty of Arts, Dunarea de Jos University of Galați, România
} 
representation of the human body; nudity would almost disappear from the artistic themes and the concerns of the artists during the respective period and left to the depiction of Adam and Eve couple, as symbol of the original sin or the Judgement Day scene when resurrected humanity awaits its verdict in the divine trial of the divorce of good from evil.

We accounted for the Renaissance which meant man's spiritual rediscovery, it reintroduced nude representation in plastic arts as essential entity of the universe and not as element of sin. The Italian ideal also marked the thought of the Nordic artists who created original models of the nude. Masters such as Albrecht Dürer in Germany, Peter Paul Rubens in Flanders or Rembrandt van Rijn in Holland personally left an imprint on this field. Court art of the $17^{\text {th }}$ century created a new nude model, of the frivolous woman, exponent of an equally daring and refined eroticism.

Neoclassicism from the beginning of the $19^{\text {th }}$ century preferred heroic nude, bearer of high moral virtues. The French Jean Louis David and Jean Auguste Dominique Ingres were the creators of the classical nude that idealized anatomical data to render perfect human prototypes. Towards the end of the century, another French artist, Edouard Manet, breached this consecrated model, imposing, in its compositions, nudes without any mythological connotation simply inspired from real life with anatomical effects and disproportions inherent to a live model.

Considered by some to be bearer of profound expressive emotions and means to convey an exacerbated eroticism, by others, either approved or contested, the representation of the human body is an omnipresent motive in all its forms of visual expression for the modern and contemporary periods. Far from this image - fetish of image civilisation, nude in fine arts further remains the sensitive seeking of the human ego.

In our analysis today, we may note that through its historical contributions and artistic elaborations, the human body becomes one of the most important syntheses of our artistic culture.

Keywords: human body, nudity, human flesh

In the classical period, in Greek antiquity "around the body there used to be sacral and civic watch as if it were a wonderful thesaurus of solemn interest for the entire community". ${ }^{1}$

If, during the Olympics, one of the athletes that represented a certain city cheated to win the contest, it was the city in question that paid a high fine. "Solitary to the conscience of the city itself, for the Greeks, the pride of the beautiful body showed itself beyond aestheticism and the resorts of a mere sensation: it stood for a serious inalienable sign of civilisation". ${ }^{2}$

\footnotetext{
${ }^{1}$ Dan Hăulică, Nostalgia sintezei (Nostalgia of Synthesis), ed. Eminescu, Bucureşti, 1984, p. 167

${ }^{2}$ Ibidem, p. 171
} 
The difference between the Greeks and the barbarians, according to Thucydides, is marked in a civilising sense, from the moment nudity becomes rule at the Olympic Games.

Although the Spartan model of discipline consequently imposed the body's nude sincerity, even accepting the almost nude appearance of women in contests, it was unanimously accepted in the entire ancient world; this comes against the fact that not all antiquity thought the same as the Helladic world. Nothing can be more natural, direct, and present to our concrete experience than the human body. European art, both modern and contemporary, confirms that the role model of Ancient Greece imposes its interest in the human flesh. The nude and image of the human flesh, along with the overcoming of prejudice in various époques, will display many cases of "fatal deformations". The Greeks were the first to impose the body's natural beauty, presenting nudity as symbol of human dignity, a democratic effigy of original equality. Initially reserved to the male body, nudes in Greek art idealized the triumphs of the athletes in the arena or the representations of the deities in the religious pantheon. Later on, female nudes reached art, hence the endurance to present times of Praxiteles's Aphrodite of Knidos or the famous Venus of Milo. Body harmony was synonymous to the supreme good for the old Greeks. (Fig. 1)

Christian art in the first centuries AD, then the art of the Middle Ages came with profound changes in the representation of the human body. Nudity almost disappeared from artistic themes and the concerns of the artists during the respective period; only the depiction of the Adam and Eve couple endured as symbol of the original sin or the Judgement Day scene when resurrected humanity awaits its verdict in the divine trial of the divorce of good from evil. In Christian art, the human body was not related directly to the real world and bore little resemblance to it, circumscribing to a transcendent universe. The anatomical plot was subjected to mental schemes, and not anatomical guidelines. (Fig. 2)

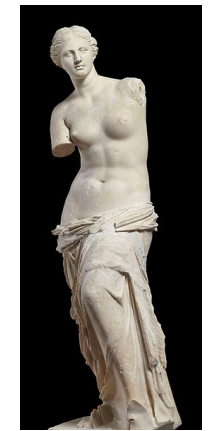

Fig. 1 Venus of Milo

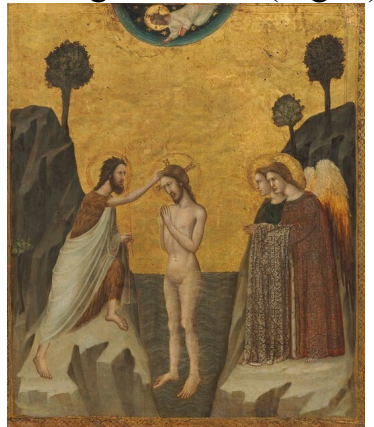

Fig. 2 Baptism of

Christ

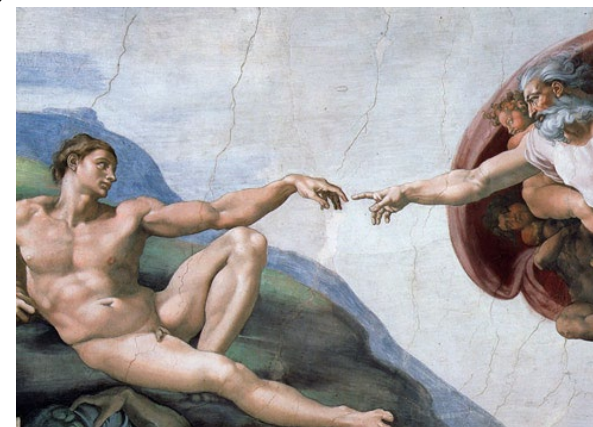

Fig.3 Michelangelo Buonnaroti Creation of Adam 
Renaissance, which meant the spiritual rediscovery of man, reintroduced nude representation in fine arts as essential entity of the universe and not as element of sin. Although they aimed at resurrecting the spirit of ancient nudity, the Renaissance artists created a new vision on the human body. The analysis and the anatomical study following nature imposed an image of the nude which was closer and closer to reality. The science of the nude as a specific Italian discipline was brought to perfection by the creations of Renaissance titans such as Leonardo da Vinci or Michelangelo Buonarrotti. (Fig. 3) They were believed to master a secret science for the ideal proportions of the human body. As a result, European artists considered study travels to Italy an obligation to make direct contact with the masters' masterpieces. Following the Italian ideal, Nordic artists created original models of the nude. Artists such as Albrecht Dürer in Germany (Fig. 4), Peter Paul Rubens in Flanders or Rembrandt van Rijn in Holland left their personal mark in this field. Dürer even wrote treatises on body proportions, believing that he discovered the Italians' secret; however, he simply managed to impose a prototype of the specifically German body. Rubens combined Michelangelo's expressive monumentality with specific forms of art in the Low Countries. For Rembrandt, the flesh was dirt that light could turn into gold. His naked fat women, lacking sensuality, were a pretext for his chromatic symphonies of lights and shadows. The court art of the $18^{\text {th }}$ century created a new nude model, the one of the frivolous woman, exponent of an equally daring and refined eroticism. Artists such as François Boucher or Jean Honoré Fragonard painted compositions of mythological themes, portraying lascivious nudes at the edge of the licentious. (Fig. 5)

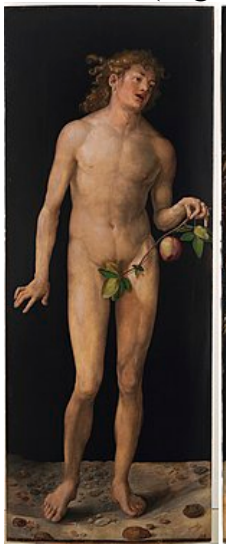

Fig. 4 Albrecht Dürer, Adam and Eve

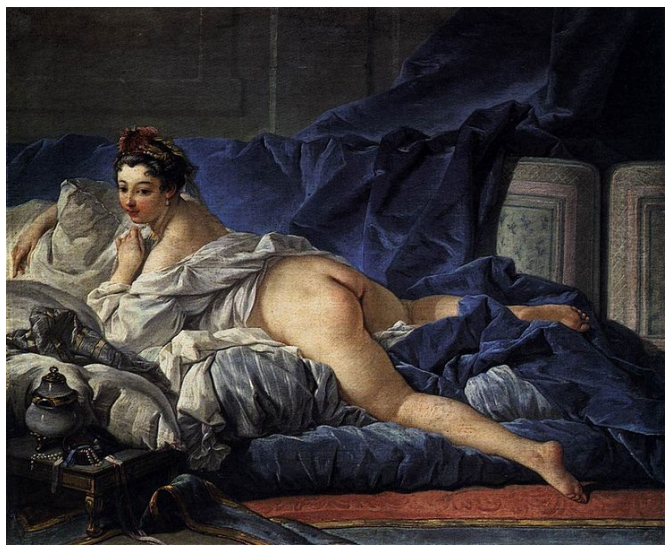

Fig. 5 Francois Boucher Brown Odalisque

The neoclassical period at the beginning of the $19^{\text {th }}$ century preferred the heroic nude, bearer of high moral virtues. Walking on the footsteps of 
their great forerunner, Nicolas Poussin, the French Jean Louis David and Jean Auguste Dominique Ingres were the creators of the classical nude that idealised anatomical data to display perfect human prototypes. Although sometimes artificial, because of too learned seeking, these nudes mostly dominated the taste of the century. Towards the end of the century, Edouard Manet breached this consecrated model, imposing, in compositions such as Breakfast on the Grass and Olympia (Fig. 6), nudes without any mythological connotation simply inspired from real life with anatomical effects and disproportions inherent to a live model. Vehemently contested during their time, these paintings marked the onset of Impressionism, an artistic current that revolutionised the art of the end of the century and decisively influenced the artistic creation from the beginning of the $20^{\text {th }}$ century. An analysis nowadays reveals the fact that, historically composed via intellectual contributions and elaborations, the human body perhaps becomes one of the most important synthesis of our artistic culture.

Along with the imposing of the human body as one of the main elements of Western artistic education in the $16^{\text {th }}$ century when European art starts to reconsider nude as artistic representation, nude becomes sort of an emblem for the artists that practiced it; this is an intellectuality emblem, similar to the case of the perspective approach of composition. The artists in question approached ideal forms of the body and space, a result of a learned meditation.

Anatomy, in search of proportions on the study of form, proposed elements of geometric idealisation. From the study of anatomy, the artists of the epoch found out about the possibility to handle science, as well as a certain intellectual elevation, thus switching from the area of mechanical art to the field of liberal arts. Nude and the human body will triumph in the era of Renaissance as an expression of intellectual ambition. In the practice of European art, nude will be regarded as a means of intellectual analysis of reality, constituting itself as a way of defence from the part of the artist against the confusion between art and life.

Nothing can be more direct, natural and present in our concrete experience, than the human body; however, the relativity of conventions is nowhere else more present than in the case of this motive, hence the particular interest in the topic. From Renaissance to the contemporary world, we do not have any instances of important artists that did not approach nude in their creation. Even the historical break with the art before them that the "impressionistic artists" engage in cannot determine a totally new attitude without drawing on the human body.

Considered by some to be bearer of profound expressive emotions and means to convey an exacerbated eroticism, by others, either approved or contested, the representation of the human body is an omnipresent motive in all its forms of visual expression for the modern and contemporary periods. 
Far from this image - fetish of image civilisation, nude in fine arts further remains the sensitive seeking of the human ego. "To speak about Renoir's nudes as if they were ripe peaches he would simply reach for, means to forget about his long battle with the classical style", claimed Kenneth Clark. ${ }^{3}$

Preserving the anatomical resemblance to the genuine model (Auguste Renoir, Edgar Degas) (Fig. 7) or integrating nude in a compositional scheme on equal position with the elements of the decorum (Paul Cezanne, Paul Gauguin), the impressionistic painters and their followers took this subject from the pedestal that the forerunners raised it to, down to the banality which lacked the fake mythological auras of the real world.

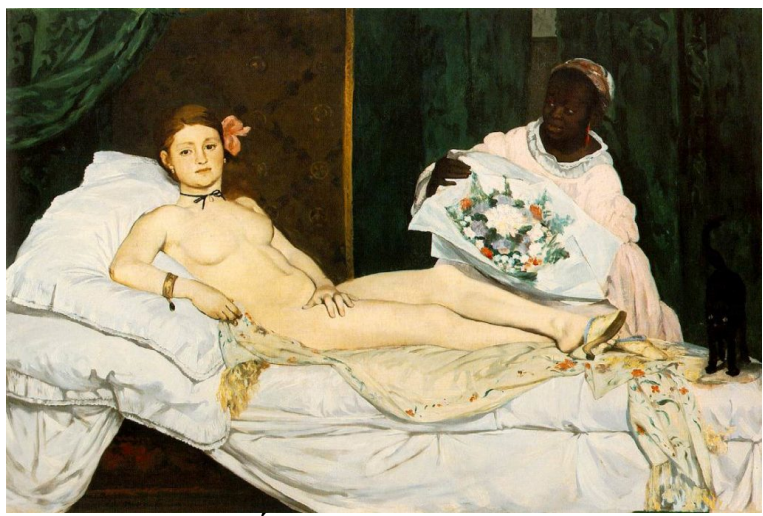

Fig. 6 Edouard Manet, Olympia

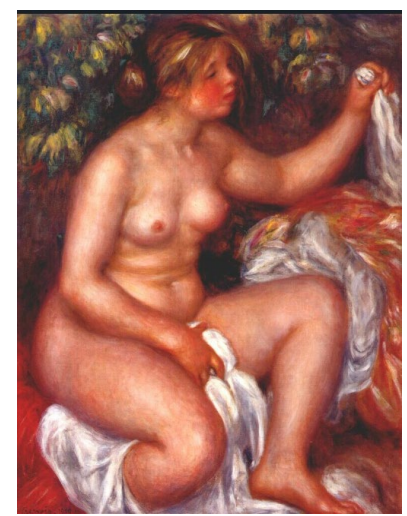

Fig. 7 Auguste Renoir, After

The fight needs to be understood here, as tension between the modern acuity of perception and refinements of the ancient art. The moderns', contemporaries' nudes often envisage a synthesis between the classical Greeks, Renaisscentists, Romantics that happily encounter on the field of evolution which comports a redefinition of painting in relation with the problematic of the moment and the millennial inheritance. Although apparently gratuitous, on the contrary, the theme of the nude implies a legitimate relation with contemporary problems and aspirations. Classical plenitude cannot be reached through the ignorance of vitality and the concrete. Similar to our contemporaries, Poussin noted the beauty of young girls and of the columns in the temple of Maison Carrée in Nîmes; on the latter, he argued that they were "no more than old copies of the young bodies of this time and since forever".

Centuries before, Vitruvius had postulated the proportions of the human body as model for architects. According to Vitruvius, in order to function as model, the human body had to correspond to the perfect figures of geometry, a square and a circle, as showed by Leonardo's famous drawing,

\footnotetext{
${ }^{3}$ Quoted by D. Hăulică in Nostalgia sintezei (Notalgy of Synthesis), p.187
} 
an image taken over so frequently by artists since those times to the contemporary era. (Fig. 8) Beyond the balance of the close forms, the human body is available for other expressions, for a dynamic dialogue with space (the ecstatic body, the pathetically discharged body, the enthusiastic body). Nike (Fig. 9), Paionios's sculpture looks as if it were walking decisively and elegantly, displaying a particular energy, a sensation of ascension for which wings seem to be mere artifices rather dictated by legend than used in art.

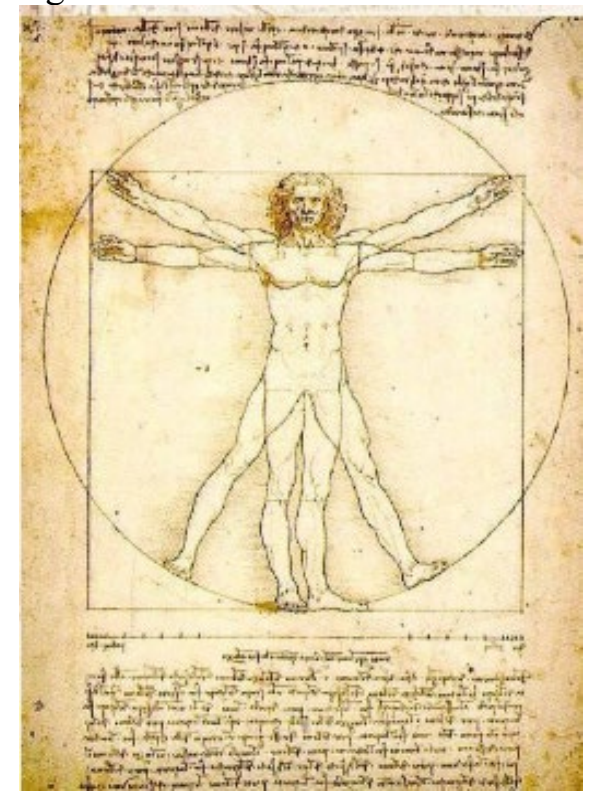

Fig. 8 Leonardo da Vinci, Vitruvian Man

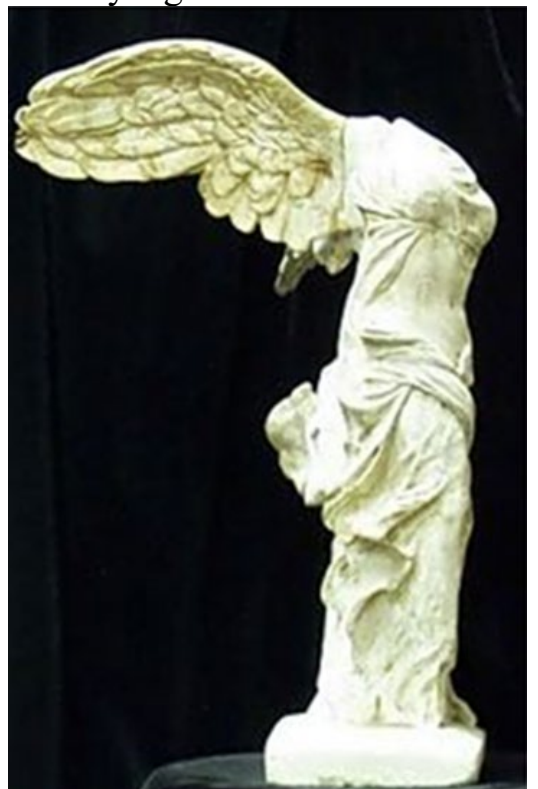

Fig. 9 Nike of Samothrace

The entirely Greek transposition, the plastic idea of the wings spreads, expresses itself in the body and its delicate harmonies. Along history, from ancient times to present day, nude implies an image of freedom and victory, remaining forever linked to the great options of human civilisation. All daring approaches or more reserved ones that contemporary artists understood to produce will obligatorily pass through the field of the nude.

The revolutionary works from the beginning of the $20^{\text {th }}$ century such as Pink nude, The Dance (Matisse) or The Young Ladies of Avignon (Picasso) (Fig. 10) are nude paintings which prove how significant the theme of the human body was for a long period of the historical developments in art. Another work, a sculpture that displays austerity and is revolutionary, as well, namely C. Brâncuşi's The Prayer (Fig. 11) stands as an example for the torments and the concerns of the beginning of the $20^{\text {th }}$ century. Approaching the theme of the nude in contemporaneity imposes a certain radicalism that engages in very abrupt interpretations. Some contemporary critics believe that an increased abstraction in the plastic resolution of the human body 
would facilitate the emphasis on the element of sexuality that the classics of European painting sublimated. However, their themes proved to be unjustified. As in classical times, in contemporaneity the "inherent ethics of the nude" needs to be brought into play. Such approaches go back to ancient times; Polykleitos perhaps rationalized the view on the human body in the strictest manner.

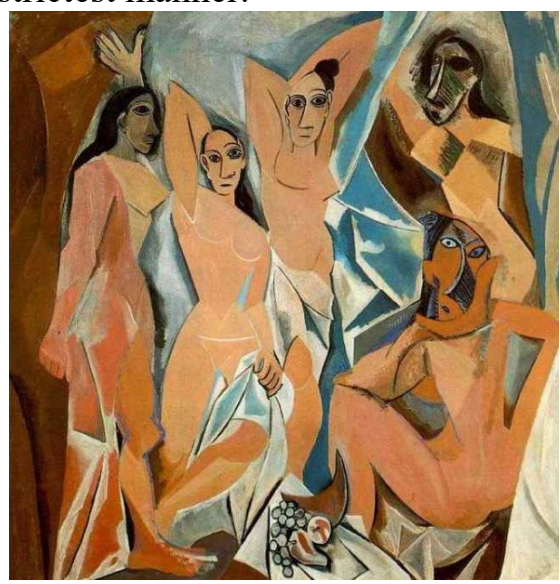

Fig. 10 Pablo Picasso, The Young Ladies of Avignon

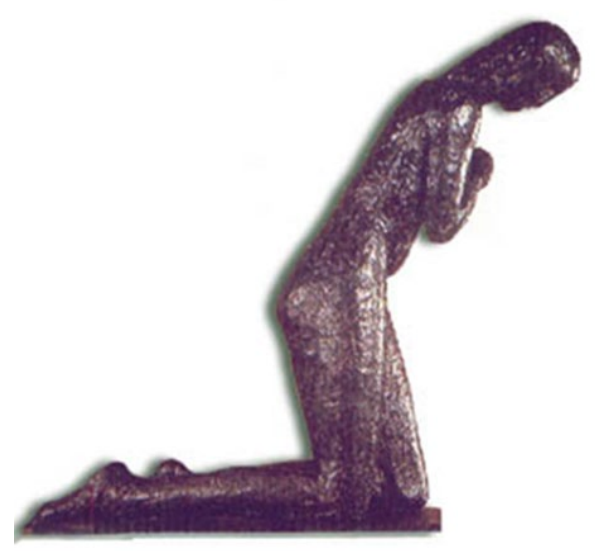

Fig. 11 Constantin Brâncuşi, Prayer

Late antiquity proposes ornamentalism in treating the body, where muscles are being dealt with plastically as armour applied to the torso. Vitruvius used to say that temple proportions should obey the ones of the human body, a condition imposed in relation to the great doctrine of macrocosm-microcosm. The doctrine has also been appreciated later since the $14^{\text {th }}$ century. Renaissance will appropriate cosmological traditions from the Hellenistic civilisation and the classical one. The fusion between what we recalled seems to have been produced since the $14^{\text {th }}$ century in the entire Western world.

The image of man with his hands stretched and height that can be circumscribed to both circle and square, fundamental figures of the universe, is the product of the fusion between the two cosmological traditions. We may find this figure in Duke of Berry's Book of Hours which materializes the symbolic and magical relation between man and universe. The figure of man that generates a square or circle will have a particular destiny in time. Along two centuries the motive will occur on all treatises of painting and architecture, dignified by Leonardo and Dürer. The image of Leonardo's ad quadratum and ad circulum man is symmetrically represented. Symmetry was understood and applied differently in works of art throughout time. (Fig. 12) Despite the prevalence of symmetry in the architecture and sculpture of the great epochs, in the case of Egyptians' painting, "care for an exhaustive 
enumeration of the elements of information rules over absolute regularity in balancing elements within the limits of the figurative plan, hence implicit symmetry of the object rather than figuration". ${ }^{4}$

Erwin Panofsky, in a study on Egyptian art showed that the artists of the period understood art as an objective transfer in raw matter of a spiritual, eternal reality susceptible to a double approach, namely sensitive and intellectual. In this case, geometry identifies itself with style. A rigorous mathematical system imposed strict methods of plastic resolution, hence the sculptures subjected to frontality and painting to profiles (examples of virtual symmetry in relation to a plane).

In Egyptian art we can easily notice that symmetry has a determinant role in the conception and materialisation of artworks.

With respect to classical Greek, art issues change as art is not simply aiming at the construction of a substitution universe anymore, i.e. the exteriorisation of "substance" to matter which endures as much as possible. At the Greeks, the law of proportions suggests movement and life.

The term of symmetry acquires a totally different meaning for them, as opposed to the Egyptians and even us, the contemporaries. Symmetry does not refer to the possible overlap between two parts of a composition in relation to a point or in relation to an axis or imaginary plane; on the contrary, it defines harmony of the parts with respect to their imaginary conception, the values implied.

Erwin Panofsky, in his study, The History of the Theory of Human Pro-portions, in Meaning of the Visual Arts, claims that Romans distinguished between the terms of proportion, symmetry and eurythmia; as far as the Greeks are concerned, he admits that "For Greek art, symmetry designates a harmonious consonantism of the part with its whole, whereas eurythmia is movement quality and proportion relating to the choice and quality of the module". ${ }^{5}$

Regarding art and figuration, the Middle Ages can be characterised by the succeeding of the two great systems of representation: the Byzantine and the Gothic one. As starting point for a formal stylisation, the Byzantine system draws on the fixed articulations of the human body, whilst the Gothic one dissociates qualitative representation of movement by the conventional structure of the bodies. Despite all these, not the entire art of the Middle Ages may be labelled as free of illusionist intentions with an intended dissociation of the representation of realistic bodily structures from movement.

Although many feel that no sooner than Renaissance had the theory of proportions been regarded as a means of expression for a metaphysical postulate, during the Middle Ages or Antiquity, image proportionality was

\footnotetext{
${ }^{4}$ Pierre Francastel, Realitatea figurativă (Figurative Reality), Ed Meridiane, Bucureşti, p. 242.

${ }^{5}$ Erwin Panofsky, The History of the Theory of Human Proportions, in Meaning in the Visual Arts.
} 
more than a technical requirement. Artists of the Middle Ages had a sensible, illusionary perception of their work, not just a schematic or intellectual one. Without continuing the discussion of the topic of the relation between symmetry and figurative canons, it is important to underline that a form-type artistic symmetry cannot exist to allow us to compare the viability of all solutions in their practical application. It was necessary to prove that, with respect to artistic symmetry, we were forced, in all epochs, to define interconnected notions in a given environment which was also relative when it came to proportions, symmetry and the figuration of the external world, in general. We need to give up the idea according to which there is a relatively stable figurative reality and that art does not constitute more than a technique of symbolical representation. Art cannot be conceived as illustration or transposition as it discovers forms of expression. The Renaissance artists (Fig. 13) will try to impose limits to a so-called rigorous determinism, rejecting the idea that the world is a faithful reflexion of an immovable thinking and perfect symmetrical character of space, not considering the viewer's position. Their works will be engaged on a new path of development, and, by seeking new rules, they will succeed in discovering another type of balance and symmetry. Unlike us, the contemporaries, when they aimed at rendering an abstract notion, the artists of the $16^{\text {th }}$ century did not search for the reference point in a text or in relation to geometry; yet, they referred to music, understood as the freest exercise of intelligence. "The system of thought that establishes a close and conscious link between the sound space and the plastic one on the field of harmonic progression, reaching a consonance, defines the unity of human behaviour for two centuries in the West". ${ }^{6}$

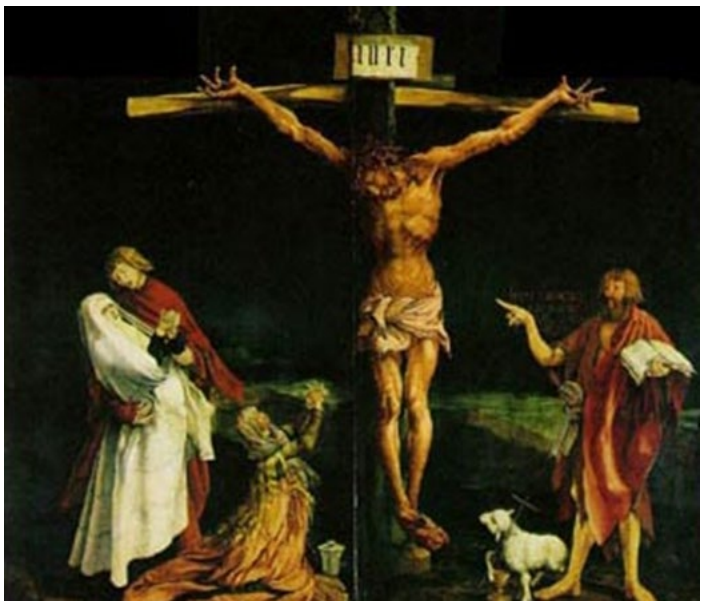

Fig. 12 Matthias Grunewald, Crucifixion

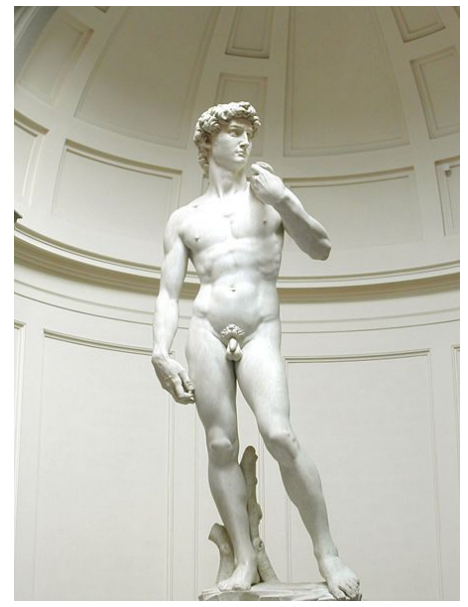

Fig. 13 Michellangelo Buonarroti, David

\footnotetext{
${ }^{6}$ Pierre Francastel, Realitatea figurativă, p. 240
} 
The reasoning of the Renaissance artists is correct if we consider that acoustic experience preceded the optical one. Harmony or consonance was the prerequisite of the time. The perfect agreement, in order to encapsulate the totality of experience, needs to admit a compromise, the ensemble of perfect balance which includes odd values. From this perspective, later on, baroque art would end classical art. Baroque art abandons the rules of frontality, without manifesting itself as an experience that creates new series of forms. The general law of symmetry is always obeyed by the artists of the time. We may discover symmetry in relation to the act of composition which influences the entire compositional thought based on compensation balance (Rubens). (Fig. 14) We will seldom encounter works in which symmetry is approached, yet, in this case, they are component parts of ensembles in which balance is restored in the end. The art of the $20^{\text {th }}$ century will unveil the aesthetic possibility of the tensions and forces in movement, besides symmetries and balance. The notions of dissymmetry and laterality have not been considered along art history to be susceptible to give birth to a system.

Romanticism proposed irregularity as a rule, conceived more as opposition to the rule and denial than principle of a new organization. (Fig. 15) The passage from this negative attitude to the search of a sensible experience based on asymmetry will occur starting with the middle of the $19^{\text {th }}$ century by the Impressionist artists.

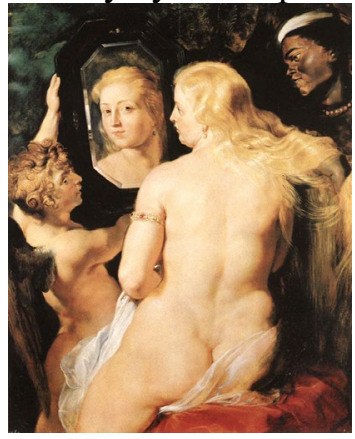

Fig. 14 Peter Paul Rubens,

Venus with a Mirror

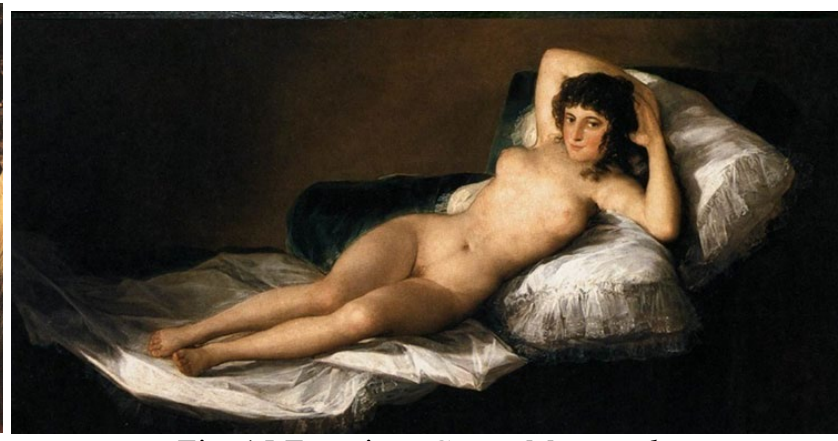

Fig. 15 Francisco Goya, Maja nuda

However, despite awarding colour the main position, the first representatives of the current will not really break with tradition. The plane of classic projections is preserved by impressionists, only light figuration moves on things and proves to be revolutionary. Only in the end of the century, through Degas, the first clues of a new figurative rule are set based on an active conception of dissymmetry. Similar to Degas, after Manet a part of the impressionistic painters propose a series of resolutions on the viewing angles. 
On Francastel's search, he notes that "For them, this is not simply about the choice of an original or oblique perspective, this word still implies the so-called distorted vision given by the adjusting of a new principle of dispersion and association of signs both on canvas and in spirit". ${ }^{7}$ As a result, there comes the need to impose a new interpretation, a speculative one of the relation of man with the universe, not automatic as in the case of the predecessors. For impressionists, man is no longer a microcosm that should quasi-symmetrically reflect a macrocosm since the world reveals itself to us as a field of forces in movement; here, our eye records the changes in matter. Renoir believed that he should attain the best painting possible. If, for Verlaine and Mallarmé, poetry did not consist in the depth of thoughts, but in the rhythmic context of sounds, for the painter nature was simply a pretext or means. In his nudes, the space of the painting is no longer the projection of the effect of perspective of the real space, as wide and deep as allowed by the clear and shiny colour range. It is not the content that generates form, but the form in its plenitude which evokes and gives content. Its nymphs, attained at maturity, recall us a new classicism, constituting in the mythological figure of the space achieved from sonority and chromatic vibrations only. For Renoir, to devote oneself to pure painting meant to focus one's research on a technique whose purpose was to produce an object, the painting considered exquisite and absolute in itself, lacking exemplary utility purposes. However, for the painting to be an ideal object, the technique of its achievement had to be an ideal one.

Despite belonging to the avant-garde group of the impressionists, Degas had been an admirer of Ingres since his youth. To the impressionism promoted by Monet or Renoir, he opposed a substantial objection: the exact sensation is in fact of the mind, before being a visual one; there cannot be another way to see without a new means to think. (Fig. 16) For Degas, the artist is not a receptor, a screen that projects "the immovable movement of Creation"; the painter is a being capable to capture reality, to bring space close to him. In his works, the space of life, the one beyond the painting is to be continued in it. On the way in which the artist understood space, Giulio Carlo Argan's work, Modern Art, reads as follows: "The gesture that renders space can no longer be the deliberate, conscious, historical one, i.e. the one that formed privileged space with an effect of perspective in classical or "historical" painting and which could only be contemplated as exemplary."

For Degas, the human body cannot be an abstract entity, always the same one; its actions have physical and psychic causes that the individual sometimes is not aware of. Japanese stamp, through the novelty of the figuration system that eliminates the corporeality of the volume and colour, melting it in the same gesture, is sign of the movement of bodies and space

\footnotetext{
${ }^{7}$ Ibidem, p. 244

${ }^{8}$ Giulio Carlo Argan, Arta modernă (Modern Art), Ed. Meridiane, Bucureşti, 1982, p. 320
} 
which would influence enormously his creation. The Japanese stamp, seen as plastic resolution in which the image is not presented as something immovable, but as rhythmic theme passed on to the viewer, acting at a psychological level as dynamic request, is also claimed by Toulouse-Lautrec in his works. (Fig. 17)

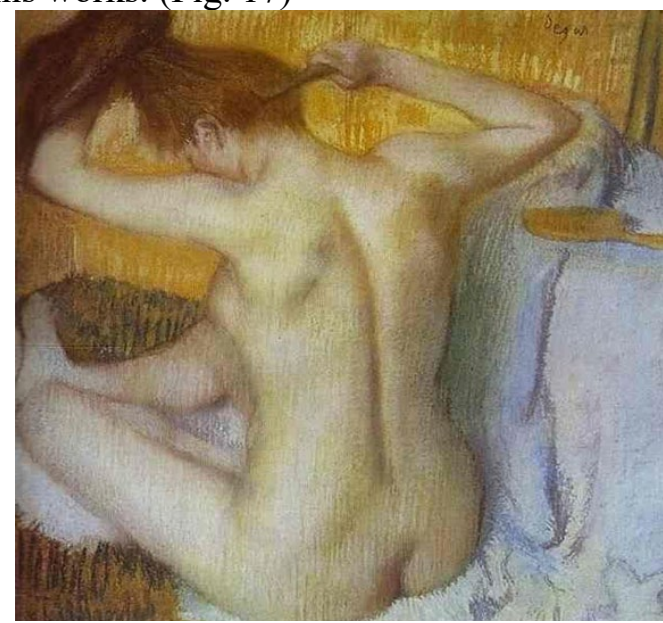

Fig. 16 Edgar Degas, After the Bath

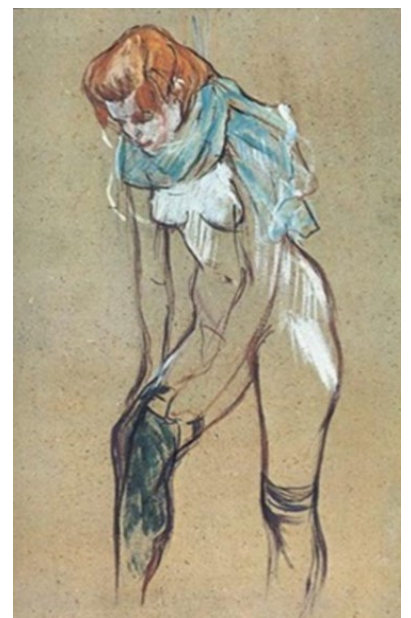

Fig. 17 Toulouse Lautrec, Tights

The great developments of knowledge acquired by man and the frequency of new discoveries, especially during the past century, harden and even prevent the perception of the world as a whole by contemporaries. The progress of electronic technology, as a result of the end of technological revolution, which imposes the need for specialization, further divided into fragments the image of the world. We may easily notice that conflict and confrontation are more familiar to contemporary man than harmony, division occurs instead of unity, whereas discontinuity replaced continuity. Gradually, the universe will be replaced by a "multiverse". Both the "rebels" and the "organizing man", the contemporaries, live together in a world in which mass media overwhelms us with information; their role is to conform or to reform, to suppress or express their personality, to seek the truth inside or outside, yet always proposing to liquidate the gap between real and ideal.

The latent disputes that the $19^{\text {th }}$ century somehow managed to balance, namely freedom and authority, democracy and dictatorship, individualism and collectivism, free initiative and economic monopoly, would outbreak as open conflicts in the $20^{\text {th }}$ century. The resulting conflicts will take the shape of revolutions, wars, whereas their other side would rise as an unprecedented diversity of artistic movements. In its turn, art becomes a weapon in the social and spiritual fight for survival.

Being a form of action, it is only natural for artists, like revolutionaries and social reformers, to elaborate manifests promoting their own "isms" and "schisms". 
As compared to the previous centuries, the $20^{\text {th }}$ century and the beginning of the $21^{\text {st }}$ century make us recall a genuine Babel Tower in which artistic doctrines and manifestations follow at an amazing speed. Within many currents, doctrines became so important that the art produced was almost insignificant. The purpose of many of these directions was to create discussions, to draw attention, to prepare exhibits and publications, yet in many cases the effect amounted to more confusion than clarity. There are situations in which these attempts either led to impasse or significant resolutions. The industrial era marks an increasing conflict between technique and aesthetics. Many contemporaries currently consider that technology opposes aesthetics.

Theorists of the industrial era show overt despise towards art values, whilst artists totally reject the utilitarian attitudes of imagery. In his theory, Kant defined art as an end without purpose and, similar to several modern theorists of mechanistic civilization, he was little cognizant of the values and aspirations of art, in general and of the art in his time, in particular.

In contemporaneity, as Pierre Francastel assesses, it is important for "sociological research, oriented towards understanding the revolutionary era in which we live, to take into account aesthetic values, after having tried to account for the relations with the technical values during our time". ${ }^{9}$ As the French thinker points out, first of all, we need to understand that there has not been and there is no natural disagreement between art and technology, on the contrary they have always been inter-connected in the history of humankind. Beauty and utility were viewpoints on the same phenomena and no products of technology and good taste existed separately since any object had a practical and aesthetic aspect by default. Art history shows us that arts rose from shaping matter and that any interference by man on matter had been there; there is also an adjustment percentage pertaining to aesthetics, to a distinct end from the simple manufacturing process. There are many formulae in the case of a tool, similar from a practical viewpoint, where the pure form only exists as abstraction. Naturally, the setting of a tool type for the safety of the collective taste element is determined. "Techniques lie at the basis of all arts, painting included, in their most gratuitous forms, apparently." 10

We already know that any technique involves certain abilities, problems of adjustment, seeking and choice of means for the achievement of the general utility scheme of the object which mainly pertains to the field of arts, namely of the taste of the one that crafts the object and the tradition of the group it belongs to. The opposition between technique and art is only justified in the case in which the work of art comes as a result of a work, useful from a material viewpoint; also, this happens when matter is shaped

\footnotetext{
${ }^{9}$ Pierre Francastel, Realitatea figurativă, p. 85.

${ }^{10}$ Ibidem, p. 95.
} 
for the purpose of expressing and promoting ideas and feelings and the artist's approach is essentially sociological in function. Furthermore, when the starting point is a motive and the artwork is produced for a propaganda purpose, art subscribes both to reality and social validity. Along with most of the public, some contemporary thinkers easily admit that the object would be ugly and art gratuitous.

The reason of these misunderstandings derives from the fact that many of our contemporaries continue to seek the values scale in the past. We agree that a part of the objects produced in the present are hideous, yet we cannot conceive that a contemporary automobile has to look like a cart or wear $16^{\text {th }}$ century clothes. Contemporaneity, due to the discovery of new materials, creates new styles and tastes before us, by associating new techniques and collective needs. However, we need to understand that safe techniques cannot offer programs as it could not be done it in the past, as well. Matter serves the artist's purposes, it does not command them, and any technique claims an external end. (Jake and Dinos Chapman, Token Pole)

The contemporary world has not changed much with respect to the relations between art and technology; everything evolves based on material and humanity's life conditions. In the old and modern world technology, aesthetics go hand in hand. If we consider the video camera, for instance, it can reproduce movement from a purely technical viewpoint. Nevertheless, without the support of art and fantasy this technical discovery of the contemporary world would have already been exhausted. Contemporary avant-garde wonderfully combined art and technology, the computer, digital camera and new materials, determining contemporary art to develop new styles and directions. Not only avant-garde currents, but also canvas painting is influenced by the new materials (holder, pigments, and various tools). The three-dimensional space suggested is no longer an opportunity, the depth implied by oil based colours vanishes, and the works solved in acrylic colours do not aim at resolving spatiality, and profoundness anymore; the rapid drying of the chromatic substance no longer affords shaping as in the case of traditional colours. The work becomes more spontaneous, fresh and full of energy. The new materials and accessories impose a new technical approach that will radically change the morphological and syntactic structure of the artwork. As in the period prior to contemporaneity, the object materializes the behaviour of an epoch; it contains utility values and social ones from which some of its aesthetic qualities derive. We would be mistaken if we believed in the absolutely gratuitous character of artworks, as in the total independence of technique. Art has never had a gratuitous character in ancient times or contemporaneity as aesthetic values cannot depart from a certain contingency. "If nowadays, in the philosophers' circles, there is a disastrous tendency to identify art with the superfluous, Bergson was mainly the one who spread this illusion. For him, the purpose of art was 
to conquer imaginary worlds; it fulfilled the imaginative vocation of humanity". ${ }^{11}$

We may conclude on the danger of these claims since they are less counter truths, than half-truths, according to Jean Przyluski: "Art (along with religion and science) is the seeker of non actual purposes; humankind shares its activity between work and play whose expression is art; languages, art, religion pertain to the functions of symbolic intelligence as the reflex of societal superstructures; it may happen for some of the objects to possess a utilitarian character which superimposes on their technical value; an artwork is sufficient in itself, the artist that creates it, and the amateur that tastes it do not aim at any other purpose besides it; finally, beauty is a substitute of the sacred." 12

The relation between technology and art has also been altered nowadays by the temptation of the gratuitous that currently affects art. If we were to accept Kantian thought according to which art is an end without meaning, the artist not aiming at anything apart from it, we should deny any significance for art. On the contrary, as Francastel did, we should accept that "... art, which served in all epochs as means of expression and propaganda, is one of the bearers of ideology in its time; we also need to acknowledge that the architect who builds a palace, a bridge or a church does not work in the absolute, beyond any contingency since his aim is to satisfy the practical needs and demands in his contemporaries' taste."13

We do not need to turn contemporary art into a simple game of the spirit lacking any practical contingency. "I believe in the crepuscule of art and ancient civilization; yet, I am convinced that another civilization is prepared for us and, without a clear distinction, we see them drawn the first shapes, especially in the field of art. Anyway, I am convinced that in order to develop itself, art has needs, before any technology... Man philosophizes after taking action and not before, whereas art is an action, similar to words, to a great extent." 14

Similar to scientists, artists are useful to the practical progress of humanity and, therefore, we need to admit the existence of a concrete relation between the speculations of contemporary art and the material and intellectual progress during that time. Also, it is important to stress the seminal role that the artwork has in the communicating thought between people and acquiescence of aspirations and needs by every era. By means of what has been previously presented, we may argue that art facilitates the fixation of images that contemporary man forms in his spirit; artists are

\footnotetext{
${ }^{11}$ Ibidem, p. 95.

12 Jean Przyluski, L'Evolution humaine, published by: Presses Universitaires de France, Published by Puf, 1942, p. 85.

${ }_{13}$ Pierre Francastel, Realitatea figurativă, p. 195.

${ }^{14}$ Ibidem, p. 197.
} 
creators of forms that will then serve as language of the time in which they live. As any language, art aims at organizing and describing the perception field of humanity, an organization which implies the creation of values more than their acknowledgement.

Any object, any sign is a collective creation, a place of encounter between people where the artist materializes, in every object, a behaviour that can only be explained based on the double need to act on the surrounding world and engage in dialogue with other people. The artist does not aim at deciphering a static universe; he shapes it continuously in an original manner, creating forms and significations at the same time. (Leon Golub, Stop Rushing Me!)

"The true sense of modern evolution after Impressionism should be sought in the changes of the notion of sign. Art ceases to be a reproduction of nature to become its interpretation, following a parallel evolution with the other forms of expression of the time, namely philosophy and literature. Let us make things clear, though: if, as any language, art holds the value of a sign, it does not mean that it draws on the other literary and written signs. It has its own means and variable, yet autonomous laws.

Throughout centuries it remains one of the great forms of communication of thought associated, not subordinated to the ones that adopt writing to manifest themselves and pass on knowledge from man to man and medium to medium." 15 Modern painting and drawing managed to free themselves from the notion of imitative representation of reality, making the existence of the plastic sign possible. Although artists precisely express themselves in terms of figurative objects and not language, art is willing to join the other activities of contemporary society.

The figurative function which defines artwork is a category of thought as complete as others with the possibility to reach direct elaboration, starting from the breaking from the works which account for their own reality, meaning, logic and structure; also, the latter do not require the need for transfer and relation with verbal systems. In the 1940s, Henri Matisse used to say that every work is an ensemble of signs invented during execution and for the necessities of the place. The moment they are taken away from their context of creation, these signs lose their value. The sign is determined the moment it is used for the object it needs to take part in. Though these words, Matisse manages to clarify the problem of the so-called "dressing" of the ideas in signs.

Any visual perception is not simply pure, it comes as the product of a spiritual activity, where the retina accounts for a "fragment of the brain". We cannot and we do not have to pretend that the role of figurative art is the mere projection on the plastic image medium of an objective copy of the sensible

\footnotetext{
${ }^{15}$ Pierre Francastel, Cahiers internationaux de sociologie, published by: Presses Universitaires de France, 1970, p. 123.
} 
reality; the aim is to propose ideas previously formulated in spirit, in a superficial form. The artist does not only record sensations, but also "a show of objects taken over from outside in his individual activity". The human eye is not an isolated sense, we only see what we know, and the retina does not show more than a gathering of immediately identifiable objects in a well established framework. We perceive and distinguish only those things that correspond to determined demands by the levels of culture. In this case, the object seen depends on other forms of knowledge.

Only the plastic image directly addresses the brain without requiring an intermediate verbal link, it manages to grasp and record events that escape other means of information and expression. From the perspective of the above mentioned, we can claim that the role of art is to give people the possibility to make known, through specific means, the values that can only be seized and noted through an autonomous system of knowledge and activity. There is plastic thought, as there is verbal one. The moment we mistake imitation for representation, there will be reluctance on the autonomous character of art, as well.

Any acknowledgement is based on memory and we simply have the possibility to recognize things to the extent to which we give them meaning, that is a reality, through education or individual imagination. In art, the point of view creates the object and, if the relations of the image are rational, not objective, the plastic sign is an invention.

As Matisse claimed, plastic signs melt in systems that bear significances in memory and imagination, not in reality.

Artists conceive "form" rather as an orientation framework, than a limitation.

"The distinction between forms - a series of random objects, monuments or paintings, which constitute styles and Form, the principle of organization, model, not concrete, but invented and organized in the plan of imagery, will form types that serial works reproduce and is capital". ${ }^{16}$

Luis Juvet believes that anything consist in the way of execution. Therefore, in essence we need to understand that art is not only speculation, a dream, but also an act, a path of knowledge, not being able to be assimilated as a secondary form of idea manifestation, from this viewpoint. The plastic sign is, by its nature, a specific one, different from the verbal sign. In figurative thought, both the relation between real and imaginary and the signifier-signified relation differ from verbal thought. The figurative sign is more mobile and ephemeral, related more to the constellation act that produces constitutive works of homogeneous ensembles than to the verbal sign. It cannot assimilate the plastic sign with the phoneme.

\footnotetext{
${ }^{16}$ Pierre Francastel, Realitatea figurativă, p.113
} 
Through the lenses of the aspects tackled above, we may summarize that art cannot be understood as an accessory form of human possibilities to give shape to the data of its senses. $20^{\text {th }}$ century art will restore the dialectical relation between man and universe. The encounter of the western civilisation with Asian and African-American civilisations which occurred at the beginning of the $20^{\text {th }}$ century will help the artists of the period to understand that the problem of configurations is that of the present relations between sensations and the frameworks of memory; it provided some of the open means of thought and human action. The artist's task is that of the man nowadays: apart from the capacity to reproduce and suffer the consequences of an acquired conduct, he has to change the relative order of acts and representations.

Artistic creation does not imply the idea of discovery or that of invention of all constitutive elements of the form produced. The drafting of form reminds us more of fluctuation than of creation. The means of expression and ways of human action undergo a continuous state of change.

People take part differently in all levels of knowledge and culture. No man can be completely representative of a type or group.

Art acts according to a reason of its own and the works produced reflect the material and intellectual reflux of other spiritual activities. Art does not consist in the presentation of models, actions or innate thought born outside it. It is a specifically human activity which manifests itself at individual level and then becomes an institution. Art generates a collection of artistic objects and also testifies to a particular type of rationality. The works of art belong to the category of civilisation objects along with certain institutions and verbal activities. Art tries to define a capability that may turn into act by means of a technique, its finality being the elaboration of type. It needs to subject technique to reach imaginative, not real goals. Unlike his old counterparts, the contemporary artist does not dispose of a single set of conventions to represent form and space. As our illustrious predecessors, we do not have a unique style as standard form of representation.

The availability of information throughout art history makes the contemporary artist aware of the great variety of the representational approaches used; therefore, he could easily choose the most appropriate working method for his expressive needs or, if it was not possible, he had the liberty to invent a new style. Along his creation, Picasso chose and used various means to tackle the problem of representation based on immediate need.

There are situations in which he opted for representational conventions, dealing with the motive in a manner that almost recalled Renaissance; however, there are also situations in which he will go as far as the cubist system of analysis (The Young Ladies of Avignon) (vezi Fig. 10). Pablo Picasso was equally considered the greatest innovator and destroyer of 
$20^{\text {th }}$ century art; he distorted and metamorphosized the human body until it stopped being nude and became an almost abstract symbol for the intensity of psychic feelings. It seemed it reached the threshold of non-figurative art and would disappear as artistic subject. New currents brought it back to the pipeline. Surrealism which was concerned with the richness of oneiric states and the mysteries of the unconscious drew on the theme of the nude as an essential subject. Artists such as Salvador Dali, René Magritte or Paul Delvaux prioritised the nude in their creation. Hyperrealism employed the nude to achieve images in which he presented as thoroughly as possible the motive in order to compete with photography.

Different representations, according to model, feeling and issues that the contemporary artists dealt with, make sizeable the differences in approach from one theme to another.

Along with the exhibit of The Fountain by Duchamp under the pseudonym Mutt, the mindset of the artwork changes radically. A columnist of the time wrote that it was irrelevant if Mutt manufactured the fountain manually. He said it did not have any importance since he chose it, took that common element of existence and presented it in such a manner that its utilitarian significance disappeared under the new title and viewpoint. Duchamp created a new thought for that object.

In 1925, in his artist's workshop, Felice Casorati prepared for a work session with model. He was absorbed by the nude beauty of the woman, the plenitude of her shapes so that he ignored the arrival of a good friend to his workshop. He sat near the model without even taking his hat off and meditated. Looking at the painting, the painter realized that, in a strange and unexpected manner, "The painting made itself!", as Casorati exclaimed. It was not the one he was worked on, but the scene he was witnessing. He was left with the option to consider painting not what he had intended, that is the model, but a nude beauty and a dressed character, each composed in their posture as in armour. He would call the canvas "Platonic conversation".

Duchamp defined this situation as an experience of the object found, a characteristic of the ready-made. This experience facilitates the interference of an object discovered randomly or picked deliberately. This product of the hazard imposes itself not as object, but as work; therefore it needs to be proposed and exhibited, to suggest and present a process of dissociation and condensation.

Duchamp speaks about ready-made, whereas Casorati brings the platonic conversation into play. Duchamp and Casorati praise eroticism for the sake of it, an event with no author or subject. In the Italian's painting, the author of the discovery is beyond the canvas. The German painter Schad joins the game by turning upside down the disposition proposed by Casorati. The work "The artist and his model" shows the painter in the foreground and the naked woman in the background. The work passes for more than sensual 
dare, a pictorial daring. The painter proves to be an author of situations and his portrait is that of a director. He could only associate the nude to the acts that gave him credit, the aspects of the theatrical scene. If we were to characterize the spirit of the time, one word only would be relevant, i.e. unrest; in the theatrical or painting representation, anguish was determined. The expressionist paintings depict the tragedy of the tough years for Germany and Austria. Otto Dix's painting, "Three women" draws on the myth of the three graces. Stylisations, the rhythm of the drawing, the interest and curiosity for anatomy prove that taking on illustrious models reflects the perfect recall of art history while simulating its oblivion.

Expressionist nudes propose a game of densities, of the pondered imbalance of forms, either too thick or too thin. We cannot speak about a type of architecture of the ensemble, harmony or scientifically calculated distributions. The human body has always been the focus of representation in the European tradition of painting. The iconography of the body reflects the philosophical and ideological development of cultures, whereas its history shows the extent to which aesthetic and legal motivations, emotions and institutions are connected.

Towards the end of World War Two (year 1944), the antiquarian Audry brings to Picasso a nude on a canvas in his workshop; the artist refuses to repaint it and shows it to all his friends that visit him. "The moment the painter prepares to ask for a picture of the painting to the photographer Brassai, inspiration suddenly strikes him: he would mime the painter before his canvas while his friend and actor Jean Marais played the role of the model, lying down before the painting in a similar position to that of the character painted on canvas" ${ }^{17}$. The mise en scene, signed by Picasso was then photographed by Brassai. The event suggests that the artist took less interest in the opulence of the female body, which was left in the background, and prioritised the relation between painter and model. Modernity had to come for the deformed body and its breaking into pieces to stop being the place of symbolic or narrative organisation. On another occasion, a mere referee, the human body equally became a phantasm of the idea of painting. The issue of representing the female nude, in Picasso's case, is almost an accessory. Instead, what matters is the reflection of the artist who sees in the theme of the painter and of his model, the archetype of the creation process. The setting does not concern the human body, but the artist's workshop and painting.

The creation of another great artist of the $20^{\text {th }}$ century, Matisse, reflects the faith that art may still hold the supreme truths of existence, the infinite harmonies of the universe.

Giulio Carlo Argan argues in a few works, that Matisse's painting could be the last echo of the classic conception of art: "The wide and precise

${ }^{17}$ Le nu (on Picasso), Ed. Gründ, Paris, 1999, p. 251. 
outlines, the large and smooth areas of the colours spread, a particular interest in things, a total reduction of time fluidity in a space that gives up the third dimension in order to be precise and shows itself at the surface". ${ }^{18}$

Matisse's work is a decisive reply to cubism, a counterpoint to the rational analysis of the object in the synthetic intuition of the whole. Matisse's "Dance" interprets, through the metaphor of the frenzy rhythm, the image of a civilisation that does not forget anything and positions all things together - semiotics, dynamic networks, trying to commute the time of history in the present, the time of knowledge and the exotic spaces on the planet. Without a shadow of a doubt, "Dance" is a work of synthesis, of the complexity expressed by a full outgoing simplicity.

Painting, in which music and poetry mingle, is conceived as a type of architecture of tense elements, in an open space, synthesis of symbol and corporal reality, volume, line and colour.

Matisse identifies synthesis as unique supernatural beauty, beyond the classical and romantic beauty. The beauty intended by the artists needs to imply and solve in itself the ugly, as well - its opposite since, in order to become universal, beauty needs to be counterbalanced, too. For Matisse, the beauty cannot be a finite form, but a continuous and rhythmic one. Human bodies stretch and bend themselves in a rhythm that transforms them and their particular beauty, a physical, not cosmic one, which cannot be broken from its space of movement. There is no static balance and regular rhythm. In this painting, Matisse acts beyond all registers, ranges and chromatic agreement that the human eye was accustomed to by the experience of nature.

In a letter, he made the following confession: "... for a beautiful blue sky, the bluest of them all (the surface is coloured until saturation, that is to a point in which it finally occurs the blue, the idea of absolute blue) and which also goes for the earth's green, and the scarlet red of the bodies." 19

In Reclining Nude dating from 1927, eroticism, once removed, makes room for the theme of diffuse sensuality. The painter confers to the constitutive elements of composition (table, wallpaper, the objects present) the same materiality as to the human body. The effect intended by the artist is obtained by the reclining nude, back, who thus signals her dedoubling: despite the model's abandon of the painter (painting, that is), in its manifest projection - body, form - the character represented enjoys the same emphasis. The young girl sleeps with one arm stretched, in a gesture of consented rest, while the remaining parts of the body do not seem abandoned, at all. Sleep detaches oneself from the daily chores, silently sweetens traits, hence the isolation and stress on interest in architectural structure for the

\footnotetext{
${ }^{18}$ G.C. Argan, Arta Modernă (Modern Art), Ed. Meridiane, Bucucureşti, 1982.

${ }^{19}$ Le $n u$ (on Matisse), pag. 232.
} 
distribution of the parts, simply put, for the form that it appropriates and strengthens. The model, thus stretched and articulated, gives the decorum a show from which it departs, becomes abstract and no more than a simple object to be offered.

"First things first, I do not create a woman, I draw a painting", claimed Matisse in the 60s, as an artist that knew many things about the image as tool of exploring the painting. Nude with Oranges is among Matisse's last works. It depicts a female silhouette drawn in ink and surrounded by oranges cut out of painted paper. The prevalence of the spiritual and emotional element in these last works was signalled not once and it is not by mere chance that the painter approaches nude iconography in the garden which draws on the myth of the joy of life. Any trace of his academism and celebrity are gone; what remains are the decorating elements disposed on a neutral background, voluptuousness of the image and the brush works which preferred to leave the trace of its own revival than hesitate. As in the famous series of blue nudes, the body moves in an indefinite unlimited space which evokes the one of the sculpture and where silhouettes are cut from coloured paper. Now the artist's aim is not to take into consideration the unseen. The space is no longer painted as it used to be in the past, but revealed. A canvas by the English Francis Bacon, dating from 1949, renders a character seen from the back and surprised the moment it left the scene and went to the backstage. If we examine it carefully, we will discover all the elements proper to Bacon's style. Even from its title, Studies from the Human Body, the painter draws our attention to the aims of the work, namely the human body, not the nude. Consequently, he makes reference to a physiological universe, the radiographies and medical photographs that covered his workshop walls. "To paint is to project your nervous system on the canvas", said Bacon, as if he wanted to diminish the emotional tension lying at the base of his creativity, to a physical phenomenon. The colour applied on an unprepared medium, as often happens, underlines the lack of depth in the scene, the space of the painting being crushed bi-dimensionally. The artist does not aim at the representation, but at the painting. Subjected to representation, the body is the scheme of the art and of the nervous system at the same time.

The most proficient critics have never ceased to lay emphasis on the primacy of painting issues in the work of Bacon. Bodies are not huddled up or stretched to show pain or anguish, but to be painted. It is not the tension of torture that embodies them, but of the painting.

The most efficient "aesthetic armour" for the nude which endured in time, is the artist's capacity to propose and impose an adequate means of reading which avoids promiscuity and obscenity. Similarly to his forerunners, the contemporary artist needs to develop that "frankness" which will ultimately constitute nude as form of artistic contemplation, casting it away 
from the obscene and the ridiculous. Finding the correct plan of reference, not abolishing under any circumstance the adherence of the work to life, is the conviction that the contemporaries need to approach the theme of the nude. Frankness defines the contemporary attempts in question where the most important ones aim a reviving the language of the human body, often going as far as the casting (Segal or Kienholz). Body Art pushes frankness even further replacing the image of the body in fiction by the living body itself, as material, not just as object of expression. Since Documenta 5, Rudolf Schwarzkogler proposed a sort of "narcissism of the ugly", and Lucas Samaras's demonstrations, dating from the same period, also proposed to us an "exasperating autobiography of the body"; an autobiography of meaningless events based on late Dadaist slogans. Some advocated that "Everything is art". Their artistic endeavours fell prey to mannerism, alternating between "insipid and sinister". However, the use of the human body itself as instrument which projected a series of significant "anxieties", may be deciphered in Yves Klein's works. The artist impregnated models with a coloured substance and by means of their contact with the plastic medium, he obtained interesting imprinting called "anthropometries". The seeking of some artists such as Jean Ipoustégui are also interesting as they bring together anatomism, spontaneous observation and cold accuracy. His works display a certain expressionist force and the drawings also describe an acute universe of the nude, forming genuine radiographies of muscular tension.

The agenda claimed by many contemporary artists proves to have been meant to show "Man" in the hypostasis of the area of emblems with cultural dignity. The anatomy imposed in its true sense is illustrated as purified of all sentimental strings, subjected to an absorbing attention that recalls Renaissance figures such as Pollajuolo or Signorelli.

The glory of the human body also combines a particular nostalgia of the indefinite and the informal in contemporary works. Contemporary artists partly aspire to renunciation of the unified body, envisaging it in more comprehensive series; instead, they propose the convergence of those relations that account for the demanding tension between irreducible individual quality and quantitative expansion specific to our time, the consumer society. Employing the arte povera means, the Italian Mario Ceroli who starts from the patterns of classical cultural heritage, namely Michelangelo's David, succeeds in impressing due to the transposition of the famous bi-dimensional sculpture in a poor material consisting of wrapping boards.

Beyond the acknowledged nobility of "classic" materials, the investigations on the theme of the nude may take the shape of any material, the effect of surprise showing in the use of the least prestigious materials.

In addition, following Rodin's oldest lesson, one may lead 
investigations by isolating certain details, through voluntary fragmentation. Out sizing detail, artists such as Claes Oldenburg propose the monumentalisation of an anatomical element as an emblem that may be seen to such dimensions so that it dominates an entire urban ensemble. This shocking monumentalisation implies a new relationship close to the human body. Other contemporary works witness an amplification of the fragment which recalls more anguish and less poetics. The fragmentary and anatomical precision, the amplifying of the anatomical element to the easy deciphering of the accidents on the living surface propose an isolation of the fragment which rather makes it disturbing and annoying to our ambient. Other contemporary artists who see the human body as an exhausted theme, often compromised by academist treatment, try to renew it by supporting it on the resorts of a certain challenge, as in the area of video art and cinema; here, it is often drawn on the prestige of the human body in a decadent way, hence the formula of the sexy movies. However, motion pictures such as Andy Warhol's Flesh prove to us the opposite. The joyous "salvation" of the human body proposes, in this case, the need for beauty, succeeding in cancelling the shock caused by the intended unbearable images at the beginning of the movie. Beyond them, the artistic gesture, a radical one on purpose, remains serious and the approach and its intentions lack frivolousness. The subject of the movie, inspired by immediate reality forces the artist to adopt these means to draw our attention to the tough meanings of life which often escape us.

Even contemporary dance displays naked bodies more and more often. There are many such instances: the solo work of the Portuguese choreographer, dancer and musician, the solo work of the Spanish choreographer La Ribot, the autobiographical masterpiece of Jérôme Bel and so on.

We may easily conclude that this increasing exposition of the nude body in contemporary dance complicates, to a certain extent, what was once called Dance without any problems.

Present in artistic endeavours throughout history from ancient times to present day, nude implies an image of freedom and vengeance, remaining forever related to the great options of human civilization.

\section{List of illustrations:}

Fig. 1 Venus of Milo, $2^{\text {nd }}$ cent. BC, presumably by Alexandros of Antioch, Louvre Museum, Paris, France

Fig. 2 Baptism of God

Fig. 3 Michelangelo Buonnaroti, Creation of Adam, 1511, Sistine Chapel, Vatican, Rome, Italy

Fig. 4 Albrecht Dürer, Adam and Eve, 1507, Prado Museum, Madrid, Spain 
Fig. 5 Francois Boucher, Brown Odalisque, 1745, Louvre Museum, Paris, France

Fig. 6 Édouard Manet, Olympia,1863, Orsay Museum, Paris, France

Fig. 7 Auguste Renoir, After the Bath, 1910, Barnes Foundation, Merion, USA

Fig. 8 Leonardo da Vinci, Vitruvian Man, 1492, Gallerie dell' Accademia, Venice, Italy

Fig. 9 Nike of Samothrace, approx. 190 BC, Louvre Museum, Paris, France

Fig. 10 Pablo Picasso, The Young Ladies of Avignon, 1907, Museum of Modern Art, New York

Fig. 11 Constantin Brâncuşi, Prayer 1907, National Museum of Art, Bucharest, Romania

Fig. 12 Matthias Grunewald, Crucifixion, 1510-1515, Unterlinden Museum, Colmar, France

Fig. 13 Michellangelo Buonarroti, David, 1501-1504, Gallerie dell' Accademia, Florence, Italy

Fig. 14 Peter Paul Rubens, Venus with a Mirror, 1614-1615, Private collection Fig. 15 Francisco Goya, Maja nuda, 1797-1800, Prado Museum, Madrid, Spain

Fig. 16 Edgar Degas, After the Bath, 1885, The Hermitage, St. Petersburg, Russia

Fig. 17 Touluse Lautrec, Tights, 1894, Toulouse Lautrec Museum, Albi, France

\section{Bibliography:}

Argan, G.C., Arta Modernă (Modern Art), Ed. Meridiane, Bucucureşti, 1982.

Francastel, Pierre, Cahiers internationaux de sociologie, published by: Presses Universitaires de France, 1970.

Francastel, Pierre, Realitatea figurativă (Figurative Reality), Ed Meridiane, Bucureşti , 1972.

Hăulică, Dan, Nostalgia sintezei (Nostalgia of Synthesis), Ed. Eminescu, Bucureşti, 1984.

Le nu, Ed. Gründ, Paris, 1999.

Panofsky, Erwin, Meaning in the Visual Arts, University of Chicago Press, 1983.

Przyluski, Jean, L'Evolution humaine, published by: Presses Universitaires de France, Published by Puf, 1942. 